\title{
El Chicosapote o Nispero en Florida 1
}

Jonathan H. Crane y Carlos F. Balerdi ${ }^{2}$

Otros nombres comunes: En inglés-Nasberry, Chikoo, Chiku, Dilly. En español-Chicle, Chicosapote, Níspero, Zapote, Zapotillo.

Sinónimos: Achras sapota, Manilkara zapota, M. achras, A. zapota, Sapota achras.

Familia: Sapotaceae.

Otras plantas en la misma familia: Mamey sapote, canistel, caimito, caimitillo, lucumo, sapote verde y abiu.

Distribución: México, los Estados Unidos, el Caribe, América Central y del Sur, Asia, India, Sri Lanka, Filipinas, Palestina, Australia, Nueva Zelandia y Africa del Sur.

Importancia: Los nísperos son muy importantes en México, América Central, el Caribe, la India y algunos países asiáticos.

\section{Descripción}

\section{El Arbol}

El níspero es un árbol de tamaño mediano a grande, especialmente después de 15 o más años de haberse establecido. Son árboles majestuosos que crecen lentamente pero poseen una larga vida y que después de muchos años pueden alcanzar una altura de 60 a 100 pies. Están bien adaptados a los climas tropicales y subtropicales.

\section{Las Hojas}

Las hojas se disponen al final de las ramas y son perennes, rectas y aguzadas y poseen una longitud de 2 a 5 pulgadas.

\section{Las Flores}

Las flores son pequeñas, de color blanco pálido y tienen forma de campana. Su diámetro es alrededor de de pulgada, son bisexuales y brotan en las axilas de las hojas.

1. Este documento, HS1035, es uno de una serie de publicaciones del Departamento de Horticultural Sciences, Servicio de Extensión Cooperativa de la Florida, Instituto de Alimentos y Ciencias Agrícolas, Universidad de la Florida. (UF/IUFAS). Fecha de primera publicación: 1994. Repasado October, 2005. Por favor visite nuestro sitio web EDIS en <http://edis.ifas.ufl.edu> or http://fruitscapes.ifas.ufl.edu.

2. J. H. Crane, Professor, Tropical Fruit Crops Specialist, TREC, Homestead; C. F. Balerdi, Professor, Multicounty Tropical Fruit Crops Extension Agent III, Miami-Dade County, Homestead Cooperative Extension Service, Institute of Food and Agricultural Sciences, University of Florida, Gainesville, 32611. Traducido al Español por Rubén Regalado y C. F. Balerdi, Miami-Dade County Cooperative Extension Service, Homestead, FL.

EI Instituto de Alimentos y Ciencias Agrícolas es un empleador que opera bajo Acción Afirmativa y provee Oportunidades Igualitarias, autorizado a proveer investigación, información educativa y otros servicios, únicamente a los individuos e instituciones que operan sin discriminación alguna con relación al credo, color, religión, edad, incapacidad, sexo, orientación sexual, estado civil, nacionalidad, opinion política o afiliaciones. Para más información sobre como obtener otras publicaciones de extensión, comuníquese con la oficina de Servicio de Extensión de su condado. Servicio de Extensión de la Florida / Instituto de Alimentos y Ciencias Agrícolas / Universidad de la Florida / Larry Arrington, Decano. 


\section{Los Frutos}

Los frutos son de forma redondeada a oval y de un color carmelita claro. La cubierta tiene normalmente una caspa y el diámetro usualmente varía entre 2 y 4 pulgadas. Las características de la pulpa dependen de las variedades y pueden ser carmelita claro, carmelitosa-amarillenta o rojiza. Su textura varía de arenosa o granular a suave y el sabor es dulce y agradable. Las semillas son de color carmelita oscuro-negro y brillantes, su forma es aplanada, poseen un ancho de 3/4 de pulgada y tienen un color blanco o crema en uno de los lados. Su número varía entre 0 y 12.

\section{Variedades}

Las variedades con buenas características deben tener buenos rendimientos, producir frutos de tamaño moderado a grande, con una pulpa dulce, suave y aromática y sin una textura arenosa. El Cuadro 1 muestra las características de algunas buenas variedades que pueden usarse en arboledas comerciales.

\section{Clima}

Los nísperos están bien adaptados a los climas tropicales y subtropicales. Tienen una tolerancia moderada a los vientos, sequías e inundaciones. En Florida, ellos crecen bien en el sur y en las áreas costeras, tan al norte como Tampa y la isla Merrit. Los árboles jóvenes pueden sufrir daños severos si la temperatura es de $32^{\circ} \mathrm{F}$ o menor, pero los árboles adultos pueden soportar una temperatura de $26^{\circ} \mathrm{F}$ con daños ligeros. Los nísperos crecen desde el nivel del mar hasta 9100 pies de altitud.

\section{Propagación}

A pesar de que las semillas pueden usarse para la propagación y para la selección de plantas superiores, no deben usarse para la siembra a escala comercial. Las variedades injertadas son mejores que las producidas de semillas. Los injertos laterales y de púas son los métodos más comunes. También puede usarse el injerto de chapilla o astilla. Los acodos no han sido efectivos. Use nísperos obtenidos de semillas como patrones. Cuando estos tengan un diámetro similar al de un lápiz estarán listos para injertarse. Cubra las yemas injertadas con cinta de injerto. El mejor tiempo para los injertos es al final del verano y comienzos del otoño. Los árbolitos injertados deben desarrollar un tamaño de 4 pies antes de sembrarse en el campo. Los árboles adultos con características indeseables pueden injertarse. Para esto, corte el tronco dejando sólo tres pies del mismo y píntelo de blanco inmediatamente. Los injertos laterales se realizan cuando los retoños alcanzen el tamaño de un dedo o un poco mayor.

\section{Siembra}

En Florida, la siembra puede realizarse en cualquier estación si existe un sistema de irrigación. En caso contrario, espere hasta el comienzo de la estación de lluvias. Haga un hoyo más ancho que el de la maceta, hasta el doble de la maceta. Puede añadir un puñado de abono orgánico bien descompuesto y mezclarlo bien con el suelo. No añada fertilizantes. Remueva el árbol con cuidado y deposítelo en el hoyo a la misma altura que estaba en la maceta y rellene el hoyo con la misma tierra que extrajo del hoyo. No use virutas ni tierra negra en el hoyo. Moje bien la tierra antes de sembrar, y después de la siembra forme un borde a 2 pies del tronco. Si no llueve, riegue todos los días durante el primer mes sólo para mantener la tierra húmeda, no la encharque; más tarde, riegue de 2 a 3 veces por semana. En los períodos de seca, riegue cada 10 o 14 días. Se recomienda la instalación de tensiómetros para monitorear la humedad del suelo.

\section{Estación de Producción y Rendimiento}

En Florida, la principal estación de producción de frutos maduros es de mayo a septiembre, pero los frutos pueden madurar durante todo el año. Los árboles obtenidos de semillas necesitan usualmente de 6-7 años para comenzar a producir frutos. Los árboles injertados son más precoces y comienzan a producir en del $2^{\text {do }}$ al $4^{\text {to }}$ año. Después de 10 años, las variedades buenas pueden producir de 150 a 200 $\mathrm{lb}$ por árbol. Este rendimiento seguirá aumentando hasta los 12-15 años, dependiendo de las distancias entre árboles; a partir de este momento el rendimiento se estabiliza. 


\section{Distancia y Poda}

A pesar de que el níspero crece lentamente, estos árboles necesitan un amplio espacio tanto entre filas como entre árboles para poder desarrollar su grandes copas. La distancia entre filas no debe ser menor de 24 a 30 pies, mientras que la distancia mínima entre árboles es de 15 a 30 pies.

Recomendamos las distancias de $25 \times 15,25 \times 20$ o $25 \times 25$ las que producirán una densidad de 116,87 y 70 árboles por acre, respectivamente. Las distancias más cortas $(25 \times 15,25 \times 20)$ producirán rendimientos mayores durante los primeros años de la arboleda (hasta los 10 años). El mejor diseño de siembra es rectangular y con una orientación de norte a sur en las filas.

A medida que los árboles crezcan se necesitará la poda para controlar la altura y ancho del árbol asi como para remover las ramas dañadas o muertas. Un espacio de 6 a 8 pies entre filas facilitará el tráfico de vehículos. Las ramas laterales deben cortarse en forma angular $\left(5-10^{\circ}\right.$ con respecto a la vertical) para que los árboles adquieran una forma piramidal ya que esto facilitará la penetración de la luz a las partes inferiores. La regla general para la altura apropiada de los árboles es que la misma debe ser aproximadamente el doble de la distancia que existe entre filas, i.e., si la distancia entre filas es de 6 pies, la altura debe ser 12 pies; si es de 7 pies, entonces la altura debería ser de alrededor de 14 pies. Los árboles deben mantenerse a una altura de alrededor de 15-16 pies. Si las copas se hacen muy densas, se pueden eliminar algunas de las ramas internas lo cual ayudará a que exista una mejor circulación de aire y una mejor penetración de la luz. Existen varios esquemas de poda. Se pueden, por ejemplo, podar las copas y los lados cada año o podar las copas todos los años pero los lados sólo en años alternos. Las ramas inferiores no deben tocar el suelo, pero ellas no deben cortarse. Recuerde que las operaciones de recolección de los frutos, fumigaciones, poda etc., son más fáciles de realizar en las partes inferiores del árbol. Cuando los árboles se mantienen con copas bajas estos tendrán un mayor volumen lo cual potencia la producción y previene que los árboles estén muy cargados de frutos en las copas. Si el árbol es muy alto y carece de ramas inferiores, elimine parte de la copa para inducir la germinación de yemas en las partes inferiores del tronco. La eliminación de las yemas apicales (1-2 pulgadas) en los dos o tres primeros años, una o dos veces entre la primavera y el verano, producirá un árbol más compacto e inducirá una mayor producción de ramas.

\section{Suelos}

Los nísperos están bien adaptados a un amplio rango de suelos (arenosos, rocosos y pesados), pero crecen mejor en los suelos livianos y con buen drenaje. Estos árboles están bien adaptados a los suelos calcáreos del sur de Florida.

\section{Abonamiento}

Aplique a los árboles jóvenes un 1/4 de lb de un abono 6-6-6 o similar; este debe poseer micronutrientes y un 30\% del nítrogeno debe provenir de una fuente orgánica. Repita esta aplicación cada 6 a 8 semanas durante el primer año; más tarde, aumente gradualmente la cantidad de abono aplicada a $0.5,0.6,0.75$ y $1 \mathrm{lb}$ a medida que el árbol crece. Use de 4 a 6 aspersiones foliares de micronutrientes al año, de abril a septiembre. En suelos alcalinos con $\mathrm{pH}$ alto, moje el área alrededor del árbol con una solución de quelato de hierro una o dos veces al año de junio a septiembre, comenzando con $0.5-0.75$ oz por árbol. El Cuadro 2 muestra las recomendaciones para el abonamiento del níspero.

\section{Irrigación}

El níspero es tolerante a las sequías. Sin embargo, como los árboles jóvenes o recién plantados tienen un sistema radicular limitado, el riego favorecerá su desarrollo y establecimiento. No se han determinado las necesidades de agua de los árboles adultos. Al igual que otros árboles frutales los períodos de floración y formación de frutos son importantes y se debe evitar la sequía en los mismos regando una o dos veces por semana. En la estación de lluvias el riego es menos importante.

\section{Plagas}

La polilla (Barnisia myrsusalis) ha causado daños extensos a las floraciones en algunos años. 
Los frutos de algunas variedades son suceptibles a la mosca del caribe (Anastrepha suspensa). Otras plagas incluyen a Phyllophaga bruneri (gallegos, gallinas ciegas), la escama minadora (Howardia biclavis), la escama verde (Pulvinaria psidii), la escama Asterolecanium pustulans, el minador (Eucosmophora sp.) y escarabajos (Conotrachelus sp.).

\section{Enfermedades}

No existen enfermedades importantes del níspero en Florida. Un hongo que causa la roya de las hojas (Uredo sapotae) causa daños menores. Otras enfermedades de importancia menor incluyen a:Fusarium solani (pudrición seca), Septoria spp.(mancha en las hojas), Phytophthora palmivora (pudrición de los frutos), Phyllosticta sapoticola (mancha en las hojas), Pestolozzia scirrofaciens (mancha en las hojas), antracnosis (Colletotrichum gloesporioides), sarna (Elsinoe lepagei) y mancha de las hojas (Phomopsis sp.). Consulte a su Agente de Extensión Agrícola para más información.

\section{Malezas}

No permita que las malezas o el césped crezcan en un radio de 2-4 pies alrededor del tronco del árbol y bajo la copa. Las malezas compiten por el agua y los nutrientes. Una capa de virutas de 2-4 pulgadas de espesor o una cubierta de plástico perforado pueden utilizarse para reducir las malezas y mantener la humedad del suelo. Mantenga las virutas separadas del tronco por 8-12 pulgadas.

\section{Maduración y Almacenamiento}

Los nísperos demoran de 4 a 10 días en madurar, después de ser recolectados. A medida que la estación de recolección avanza el tiempo de maduración disminuye. Los frutos deben almacenarse a $55^{\circ}$ F y $85 \%$ de humedad relativa.

\section{Usos}

Los nísperos se usan mayormente como fruta fresca. De la pulpa se pueden hacer batidos, helados y sorbetes. Existen pocos productos procesados con excepción del chicle, que en el pasado fué producido a partir del látex. 


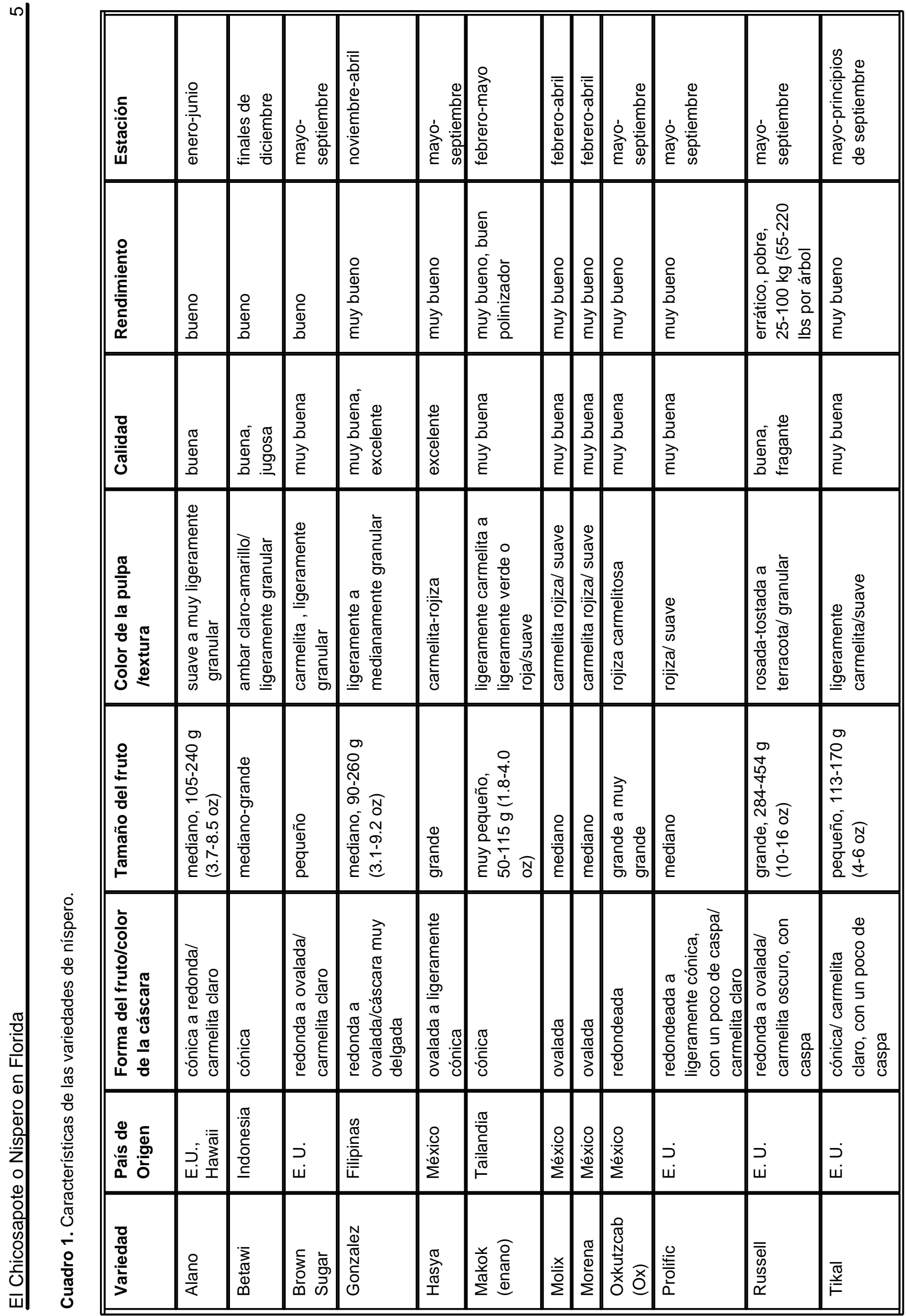


Cuadro 2. Recomendaciones para el abonamiento del níspero en Florida.

\begin{tabular}{|c|c|c|c|c|c|}
\hline Año & $\begin{array}{l}\text { Veces } \\
\text { por } \\
\text { año }\end{array}$ & 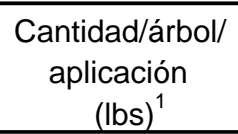 & $\begin{array}{c}\text { Cantidad } \\
\text { total/árbol/año } \\
\text { (lbs) }\end{array}$ & $\begin{array}{c}\text { Aspersiones de } \\
\text { micronutrientes (veces } \\
\text { por año) }\end{array}$ & $\begin{array}{l}\text { Aplicaciones de } \\
\text { quelato de hierro } \\
\text { (oz/árbol/año) }^{3}\end{array}$ \\
\hline 1 & 6 & $0.25-0.5$ & $1.5-3.0$ & 6 & $0.5-0.75$ \\
\hline 2 & 6 & $0.5-1.0$ & $3.0-6.0$ & 6 & $0.75-1.0$ \\
\hline 3 & 6 & $1.0-1.5$ & $6.0-9.0$ & 6 & $1.0-1.5$ \\
\hline 4 & 4 & $1.5-2.5$ & $9.0-10.0$ & 6 & $1.5-2.0$ \\
\hline 5 & 4 & $2.5-3.5$ & $10.0-14.0$ & $4-6$ & $2.0-4.0$ \\
\hline 6 & 4 & $3.5-4.0$ & $14.0-16.0$ & $4-6$ & $2.0-4.0$ \\
\hline 7 & 4 & $4.0-4.5$ & $16.0-18.0$ & 4-6 & $2.0-4.0$ \\
\hline 8 & 4 & $4.5-5.0$ & $18.0-20.0$ & $4-6$ & $2.0-4.0$ \\
\hline \multicolumn{6}{|c|}{$\begin{array}{l}\text { 1, Use 6-6-6, 8-3-9, un abono para árboles jóvenes o un abono de liberación controlada. } \\
\text { 2, Las aspersiones deben contener zinc, manganeso, boro, molibdeno y pueden contener hierro. } \\
\text { Aplíquelas de abril a septiembre. } \\
\text { 3, Las aplicaciones de quelato de hierro evitarán las deficiencias de este metal, pero no asi las aspersiones. } \\
\text { Aplíquelas de junio a septiembre. }\end{array}$} \\
\hline
\end{tabular}

